\title{
Los médicos cirujanos y la literatura
}

La afición de los médicos a escribir literatura viene desde hace mucho tiempo, así es como muchas obras literarias nacen de la relación que existe entre la medicina, los enfermos, la enfermedad y los médicos.

Algunos han abandonado su profesión para convertirse en escritores, quizá porque ya lo eran de entrada o porque la experiencia médica les llevó a creer que la literatura estaba más de acuerdo con su carácter.

Esta relación bidireccional lleva a dos preguntas inevitables: ¿porque la medicina se interesa por la literatura? y ¿por qué la literatura se interesa por la medicina? Hay múltiples respuestas posibles, algunas de las cuales comentare brevemente.

La experiencia médica asistencial es intensa, profunda y difícil de comprender pues no basta con estudiarla sino que es necesaria vivirla y comprenderla mostrando, entonces un mundo nuevo que además de apasionante deja recuerdos y experiencias que ninguna otra profesión puede dar. Puesto que trabaja con lo único y más preciado por ser humano y que nos hace a todos iguales y que es la vida misma.

Cuando el médico escribe artículos, informes y hace análisis de un enfermo y su dolencia, está haciendo un ejercicio "detectivesco" casi policial en la búsqueda de un buen diagnóstico y la cura del paciente. Es por ello que el proceso de raciocinio médico se ha comparado a una obra de ficción como las del género policíaco. En este sentido hay que recordar a modo de ejemplo al médico escoces Arthur Conan Doyle y su personaje de Sherlock Holmes.

Para muchos médicos, la narración literaria permite establecer y resaltar o destacar matices ausentes en el discurso médico tradicional e ilustrar aspectos difíciles de explicitar a través del lenguaje y de la escritura médica.

Por otra parte, si nos preguntamos por qué la literatura se interesa por la medicina, veremos que la enfermedad es una experiencia universal y la muerte, a la que puede conducir esta, es una preocupación permanente del ser humano. Es obvio que la aparición de la enfermedad constituye un elemento dramático de primer orden, ya que apela a los sentimientos más íntimos y ayuda a la construcción de un escenario de intensa fuerza literaria. Así, la tuberculosis se convierte en el elemento central de La Montaña mágica (1924), de Thomas Mann, como también una epidemia es el motivo de Albert Camus para escribir su obra La peste (1947) y algunas obras ya consideradas clásicas como Frankenstein (1817), de Mary Shelley, están mereciendo una relectura como instrumento docente para explicar la ética de la investigación médica.

La literatura también permite analizar cuidadosamente los elementos emocionales que afectan al paciente y su enfermedad, como también su repercusión en el médico siendo una veta atractiva y motivante para la literatura.

El contacto diario con el enfermo, con sus miserias, sus inquietudes, angustias y temores acerca de la enfermedad y de la muerte, llevan al médico a buscar en la literatura una forma de desahogo de sus heridas del alma (Neurosis).

El catálogo de médicos-escritores y escritores-médicos es extenso. La síntesis es Anton Chejov (1860-1904) que consideró a la Medicina como la esposa legítima y a la Literatura la amante, son frases de otros tiempos que aún perduran. Fernando Navarro escribía1 "No es nada raro que en el ejercicio de su profesión, el médico busque los aspectos más profundos de la enfermedad, el dolor, el sufrimiento, la locura y la muerte, los sentimientos o sensaciones más íntimos. En esta búsqueda, los libros médicos son de escasa utilidad: es necesario acudir a la literatura universal". William Osler en su libro Aequanimitas ${ }^{3}$ sostiene que: "para comprender los temores, las preocupaciones y los conflictos emocionales de los enfermos, a veces no hay mejor fuente de información que la literatura".

Así, entonces, la literatura le permite al Médico, adquirir las habilidades clínicas generales, entre las que destaca la capacidad para obtener una historia clínica con todos los detalles relevantes. Dice Laín Entralgo": "una historia clínica qué es si no el relato de los sucesivos encuentros entre dos personas, el médico y el enfermo". Además, la literatura le permite al Médico adquirir habilidades comunicativas, capacidad para detectar las principales preocupaciones y expectativas de los enfermos y transmitir esperanza y compasión. El médico "es un posibilitador de esperanza" ya que las palabras del médico bien expresadas, pueden ser polvo de oro para el paciente pero sin son mal expresadas pueden ser cortantes y dolorosas como un bisturí. También la literatura nos ayuda a conocer las enfermedades desde otras miradas tales como las del propio paciente o la de los familiares que la rodean.

Cuántos seguidores de Galeno han comprendido esta estrecha relación de la medicina y la literatura demostrándolo a través de sus obras literarias, sin embargo, cuantos más hubo e incluso hay que simplemente no se atrevieron a escribir sus pensamientos, sueños, esperanzas que marcaron sus recuerdos con tinta indeleble en su memoria. Así como el cirujano se prepara, se educa, se entrena y una vez listo se arriesga a la cirugía asumiendo la posibilidad del fracaso también hay otros que además de ello se arriesgan a escribir

Marti Macuer nos advierte en su novela "Si no tuviéramos miedo":

¿Se han preguntado alguna vez cuántas historias han quedado sin escribir, cuantas se han perdido o han quedado guardadas por ahí en cajas de cartón y algún día han ido a para al basurero? ¿Cuántos grandes escritores han sucumbido por miedo, inseguridad o simplemente porque se les pasó el tiempo y nadie los publicó o simplemente sus grandes novelas nunca fueron escritas?

En nuestro ambiente neuro quirúrgico el Dr. Francisco Simón Rivas Larraín, con quien tuve el gusto de compartir durante su pasantía en el Instituto de Neurocirugía, nos dio un ejemplo con una gran cantidad de obras escritas y reconocimiento en los más prestigiados centros literarios. 
Ahora se nos presenta un joven escritor de nuestra especialidad médica, el Dr. Carlos Bennett Colomer quien con su primera novela "El Desaparecedor", escrita en tiempos de Pandemia, nos habla de tres historias que se entrelazan, en un ambiente costumbrista del Valparaíso de 1930.

Es así, entonces, como los que comprenden la relación entre la Medicina y la literatura y se atrevieron a escribir nos dan un ejemplo digno de emular por aquellos que lo han pensado pero que aún no dan el salto de fe a la literatura.

Dr. Lientur Taha Moretti Neurocirujano

\section{Referencias}

1. Navarro F. Literatura médica. Diario Médico, 10-5-2006.

2. Camus A. La peste. Editorial Edhasa. Barcelona, 1996.

3. Osler W. Aequanimitas. Fundación Uriach. Barcelona, 2004.

4. Laín Entralgo P. Medicina e historia. Ediciones Escorial. Madrid, 1941. 